\title{
IN-PLANE STRENGTH OF STEEL ARCHES
}

\author{
Yong-Lin $\mathrm{Pi}^{1, *}$, Mark Andrew Bradford ${ }^{2}$ and Francis Tin-Loi ${ }^{3}$ \\ ${ }^{1}$ The corresponding author, Senior Research Fellow, Centre of Infrastructure Engineering \& Safety, \\ School of Civil \& Environmental Engineering, UNSW, Sydney, NSW 2052, Australia \\ *(Corresponding author: E-mail: y.pi@unsw.edu.au) \\ ${ }^{2}$ Federation Fellow, Professor, Centre of Infrastructure Engineering \&Safety, \\ School of Civil \& Environmental Engineering, UNSW, Sydney, NSW 2052, Australia \\ email: m.bradford.@unsw.edu.au \\ ${ }^{3}$ Professor, Centre of Infrastructure Engineering \& Safety, School of Civil \& Environmental Engineering, \\ UNSW, Sydney, NSW 2052, Australia, email: f.tinloi@unsw.edu.au
}

Received: 24 September 2007; Revised: 15 November 2007; Accepted: 20 November 2007

\begin{abstract}
A rational finite element program for the nonlinear elastic-plastic analysis of arches is used in this paper to investigate the in-plane elastic-plastic buckling and strength of circular steel arches. The finite element program considers the effects of large deformations, material nonlinearities, initial geometric imperfection, and residual stresses in predicting the elastic-plastic behaviour of steel arches. Radial loads uniformly distributed around the arch axis, concentrated loads, and distributed loads along the horizontal projection of an arch are studied, which induce either uniform compression or combined bending and compression in the arch. The complex effects of initial imperfection, rise-to-span ratio, residual stresses and the end support conditions on the in-plane elastic-plastic stability and strength of steel arches are included in the study. Useful design equations against in-plane failure are proposed for steel arches under uniform compression and under combined bending and compressive actions.
\end{abstract}

Keywords: Arch, combined bending and compression, compression, buckling, elastic-plastic, steel, strength This paper is extended from the paper presented in ICSCS07 entitled In-plane inelastic buckling and strength of steel arches.

\section{INTRODUCTION}

This paper is concerned with the in-plane nonlinear buckling behaviour and strength design of steel circular arches that are subjected to transverse loads, as shown in Figure 1. Arches resist general loading by a combination of predominant axial compression and bending actions. Under these actions, an arch which is adequately braced by lateral restraints so that its out-of-plane failure is fully prevented, may suddenly buckle and fail in the plane of its loading.

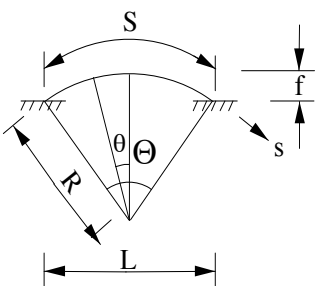

(a) Geometry

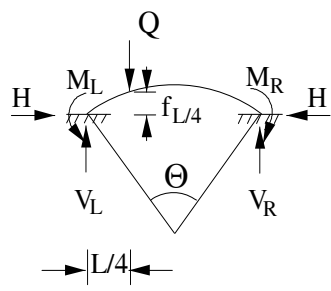

(d) Quarter point load

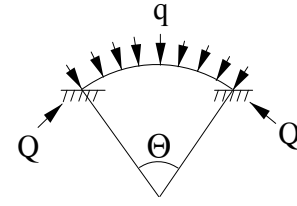

(b) Uniform compression

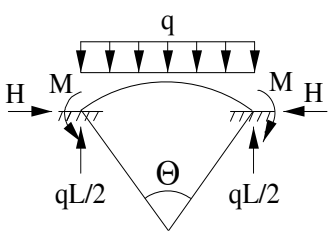

(e) Uniformly distributed load

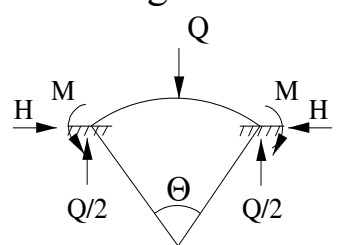

(c) Central load

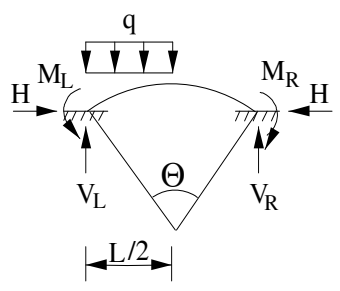

(f) Half span uniformly distributed load

Figure 1. Arch and Loading 
The in-plane elastic buckling load of arches is an important reference in the design of steel arches against their in-plane failure. The in-plane elastic buckling of arches has been studied by many researchers $[1,2,3,4,5,6,7]$. Early treatments of the in-plane elastic buckling of steel arches concentrated on the classical buckling analysis and are summarized in Galambos [8]. The classical buckling analysis assumes that the prebuckling behaviour is linear and it ignores the effects of prebuckling deformations on the buckling. However, shallow arches become nonlinear prior to buckling and their prebuckling deformations are substantial, so that predictions based on classical buckling theory may overestimate the buckling load of shallow arches [9]. Gjelsvik and Bodner [10] obtained approximate solutions for fixed shallow circular arches with rectangular cross-section, and Schreyer and Masur [11] derived analytical solutions for fixed shallow arches with rectangular cross-section. Pi et al. [12] investigated the in-plane elastic buckling of shallow arches with an arbitrary cross-section, and found that the in-plane elastic buckling load of shallow arches are much lower than that given by classical theory $[1,2,3,4,5,6,7]$ and so the classical in-plane buckling load should not be used as the reference load in the development of design methods for the in-plane strength of shallow steel arches.

Despite their widespread use, accurate research that reports on the strength and design of steel arches against their in-plane failure appears to be quite limited and has concentrated on pin-ended arches. Explicit methods for designing steel arches against their in-plane failure have not been given in many commonly-used design codes $[13,14,15]$. A few methods $[16,17]$ were proposed and were essentially based on the strength of steel beam-columns. Verstappen et al. [18] proposed that the in-plane buckling design strength of non-shallow circular arches should be determined by using a linear interaction design equation that was developed for straight beam-columns. Pi and Trahair $[19,20]$ studied the in-plane elastic-plastic behaviour of pin-ended circular steel arches, while Pi and Bradford [21] investigated the in-plane elastic-plastic behaviour of fixed circular steel arches.

The aims of this paper are to use an advanced nonlinear elastic-plastic finite element (FE) program, developed elsewhere by the authors [22,23], to investigate the in-plane elastic-plastic behaviour at failure and the strength of circular steel arches, and to propose design equations for these members against in-plane failure based on this numerical investigation.

\section{ELASTIC IN-PLANE BUCKLING}

The elastic buckling load of arches under uniform compression can be used as a reference load in the formulation for their in-plane strength design. Pi et al. [12] studied the elastic buckling of arches under uniform compression. It was found that for in-plane buckling, arches usually buckle in an antisymmetric bifurcation mode and only very shallow arches buckle in a symmetric instability mode. The buckling load for arches was obtained by Pi et al. [12] as described in the following.

The expressions for the elastic buckling loads of shallow and deep arches are different. When an arch has an included angle such that $\Theta \leq 90^{\circ}$, it is deemed to be a shallow arch and a dimensionless parameter $\lambda$ defined by [12]

$\lambda=\frac{S \Theta}{4 r_{x}}$

can be used to measure the shallowness of an arch, where $S$ is the length of the arch and $r_{x}$ is the radius of gyration of the cross-section about its major principal axis given by $r_{x}=\sqrt{I / A}$, with $A$ being the area of the cross-section and $I$ being the second moment of area of the cross-section about its major principal axis. 
For a pin-ended shallow arch, its buckling load is given by [12]

$N_{a c r}= \begin{cases}\left(0.15+0.006 \lambda^{2}\right) N_{c r} & \text { for } 3.88 \leq \lambda \leq 9.38 \\ \left(0.26+0.74 \sqrt{1-0.63 \pi^{4} / \lambda^{2}}\right) N_{c r} & \text { for } \lambda>9.38\end{cases}$

where $N_{c r}$ is the second mode elastic flexural buckling load of a corresponding pin-ended column with the same length.

For a fixed shallow arch, its buckling load is given by [12]

$N_{a c r}= \begin{cases}\left(0.36+0.0011 \lambda^{2}\right) N_{c r} & 9.87 \leq \lambda \leq 18.6 \\ \left(0.6+0.4 \sqrt{1-3.109 \pi^{4} / \lambda^{2}}\right) N_{c r} & \lambda>18.6\end{cases}$

where $N_{c r}$ is the second mode elastic flexural buckling load of a corresponding fixed column with the same length.

When an arch has an included angle $\Theta>90^{\circ}$, it is deemed to be a deep arch, and its elastic buckling load is given by [12]

$$
\begin{array}{ll}
N_{a c r}=\left[1-(\Theta / \pi)^{2}\right] N_{c r} & \text { for pin-ended arches, } \\
N_{a c r}=\left[1-(\Theta / 1.4304 \pi)^{2}\right] N_{c r} & \text { for fixed arches, }
\end{array}
$$

where $N_{c r}$ is the second mode elastic flexural buckling load of a corresponding pin-ended or fixed column with the same length.

The second buckling load $N_{c r}$ of the corresponding column in these equations is given by $N_{c r}=\frac{\pi^{2} E I}{(k S)^{2}}, \quad$ with $k=\left\{\begin{array}{cc}0.5 & \text { for pin-ended arches } \\ 0.35 & \text { for fixed arches }\end{array}\right.$

where $E$ is the Young's modulus.

\section{NONLINEAR ELASTO-PLASTIC FINITE ELEMENT MODEL}

A nonlinear elastic-plastic FE program for arches, developed elsewhere by the authors [22,23], is used in this paper to investigate the in-plane strength of steel arches. The formulation of the FE program is based on the following assumptions and considerations:

(1) use of the Euler-Bernoulli theory of bending,

(2) application of nonlinear strain-displacement relationships that allow for large displacements and rotations,

(3) inclusion of distributions of longitudinal normal residual stresses due to manufacturing and curving, as are described subsequently,

(4) inclusion of initial geometric imperfections

(5) inclusion of user-defined stress-strain relationships.

Full details of the FE program are given in Pi et al [22,23], and the effectiveness and accuracy of this model has been verified extensively. For example, the results of the FE program for the in-plane elastic buckling load of circular arches under a uniform radial load $q$ agree with the analytical solutions given by Eqs. 2-5 very well as shown in Figures 2 and 3, where $N_{a c r}=q R$ is the nominal axial compression during buckling and $R$ is the radius of the arch. Other examples are given in $\mathrm{Pi}$ et al.[22,23] and not reproduced here. 


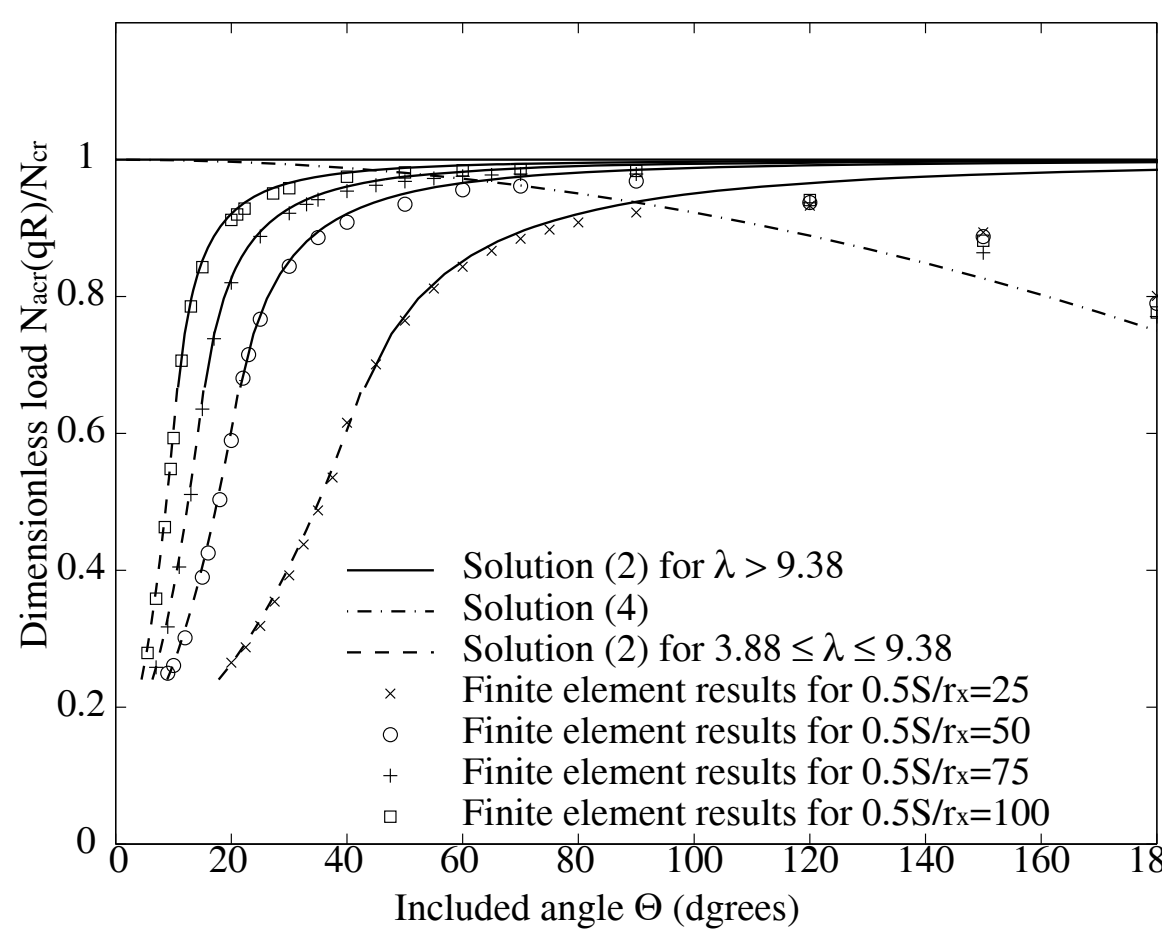

Figure 2. Comparison of FE Results with Analytical Solutions for Elastic Buckling of Pin-Ended Arches

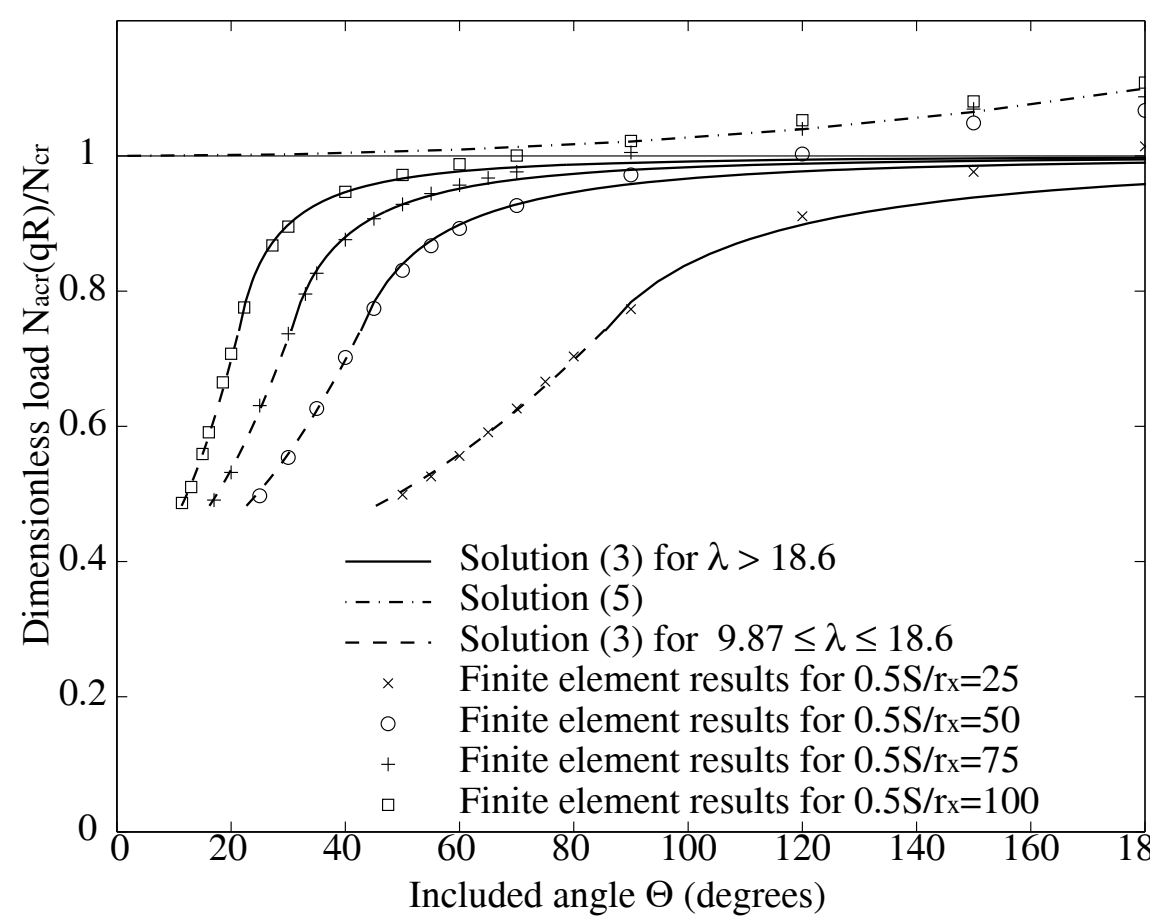

Figure 3. Comparison of FE Results with Analytical Solutions for Elastic Buckling of Fixed Arches 


\section{RESIDUAL STRESSES, STRESS-STRAIN CURVE}

Residual stresses may be induced in the manufacturing and curving processes for steel arches. It has been shown that the residual stresses have effects on the strength of steel arches, and so they need to be considered in the development of strength design equations.

The residual stresses $\sigma_{r}$ consist of two components: the manufacturing and the cold rolling (or curving) residual stresses shown in Figures 4(c)-4(d). In Figure 4(c), $\sigma_{r t}=0.5 \sigma_{y}$ is typically the tensile residual stress at the flange-web junctions and $\sigma_{r c}=0.35 \sigma_{y}$ is typically the compressive residual stress at the flange tips, where $\sigma_{y}$ is the yield stress.

Rolling residual stresses are induced in cold curving the arch. It is assumed that, for example, a straight I-section member is bent elastic-plastically to obtain an overbent arch, and then released so that the overbent arch relaxes elastically into its final shape with a permanent set. Although the depth of the plastic zone after overbending depends on the radius of the arch, and so also do the final rolling residual stresses, the final rolling flange residual stresses $\sigma_{r r f}$ are quite small after the relaxation. Hence, for convenience, the rolling residual stresses are assumed here to be independent of the arch radius.

The maximum rolling residual stresses occur in the web near the neutral axis, and so their effects on elastic-plastic buckling are quite small as elastic-plastic buckling is controlled primarily by flange yielding.

The maximum rolling flange residual stresses $\sigma_{r r f}$ are assumed to be given by

$\sigma_{r r f}=\sigma_{y}\left(\frac{Z_{p x}}{Z_{e x}}-1\right)$

where $Z_{p x}$ and $Z_{e x}$ are the plastic and elastic moduli of the cross-section about its major principal axis, respectively. The maximum rolling web residual stresses $\sigma_{r r w}$ are assumed to be given by $\sigma_{r r w}$ $=0.9 \sigma_{y}$

The residual stresses shown in Figures 4(c) and 4(d) satisfy the in-plane bending equilibrium condition

$\int_{A} \sigma_{r} y \mathrm{~d} A=0$,

while the axial force equilibrium condition

$\int_{A} \sigma_{r} \mathrm{~d} A=0$

is used to determine the mid-web residual stress $\sigma_{r c w}$, where $y$ is the coordinate in the principal axes of the cross-section, and $A$ is the area of the cross-section.

The residual stresses defined above, and the steel I-section and the tri-linear stress-strain relationship shown in Figure 4 are used throughout this study. The dimensions of the I-section are: the depth of the cross-section $D=0.2613 \mathrm{~m}$, the flange width $B=0.151 \mathrm{~m}$, the flange thickness $t_{f}=$ $0.0123 \mathrm{~m}$, and the web thickness $t_{w}=0.0077 \mathrm{~m}$. The material properties for the tri-linear stress-strain curve are: the yield stress $\sigma_{y}=250 \mathrm{MPa}$, the corresponding yield strain $\varepsilon_{y}=0.00125$, Young's modulus of elasticity $E=200,000 \mathrm{MPa}$, the strain at which the strain hardening starts is assumed to be 11 times the yield strain, the maximum strain is assumed to be 71 times the yield strain. The strain hardening modulus $E_{s}=6,000 \mathrm{MPa}$, and the shear modulus is $G=80,000 \mathrm{MPa}$. 


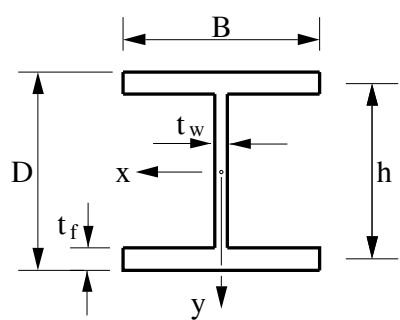

(a) Cross-section

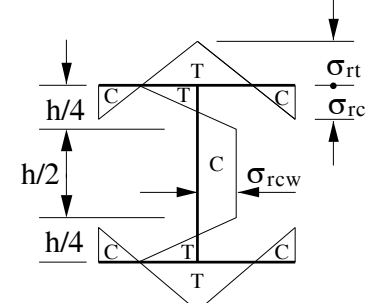

(c) Manufacturing residual stresses

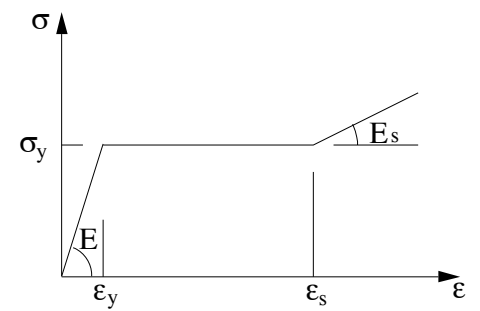

(b) Stress-strain curve

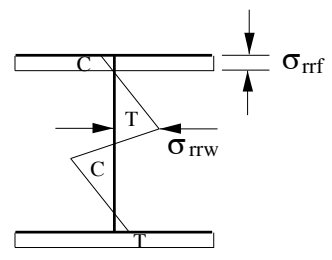

(d) Rolling residual stresses

Figure 4. Cross-Section, Stress-Strain Curve and Residual Stresses

\section{STRENGTH IN UNIFORM COMPRESSION}

The design proposal for the in-plane strength capacity $N_{a c}$ of a steel arch that is subjected to uniform compression is based on the methodology in AS4100 [13] for compression members, but modified accordingly for arches. Thus

$N_{a c}=\phi \alpha_{a c} N_{Y} \leq N_{Y}$,

where $\phi$ is a capacity reduction factor ( $\phi=0.9$ is suggested and used in AS4100 [13]), $N_{Y}$ is the squash load of the cross-section and given by

$N_{Y}=A \sigma_{y}$,

and $\alpha_{a c}$ is the in-plane slenderness reduction factor of an arch and given within the methodology of AS4100 [13] by

$\alpha_{a c}=\xi_{a}\left[1-\sqrt{1-\left(\frac{90}{\xi_{a} \lambda_{a g}}\right)^{2}}\right]$

with

$\xi_{a}=\frac{\left(\lambda_{a g} / 90\right)^{2}+1+\eta_{a}}{2\left(\lambda_{a g} / 90\right)^{2}}$

in which the modified slenderness $\lambda_{a g}$ is defined as

$\lambda_{a g}=\frac{L_{e}}{r_{x}} \sqrt{\frac{\sigma_{y}}{250}}$

with the effective length $L_{e}=k S / \sqrt{k_{a c}}$; and the imperfection parameter $\eta_{a}$ is given by $\eta_{a}=0.00326\left(\lambda_{a g}-13.5\right) \geq 0$.

In Eq. 14, $\sigma_{y}$ is expressed in units of $\mathrm{MPa}$ and the factor $k_{a c}$ is given by $k_{a c}=N_{a c r} / N_{c r}$.

To verify the proposed in-plane strength of an arch in uniform compression given by Eq. 10, the FE program was used to investigate the in-plane strength $N_{a c}$ of arches in uniform compression. 
Because the in-plane geometric imperfections have significant effects on the strength of steel arches, they have to be considered in the design formulation. In the FE analysis, the in-plane geometric imperfections were assumed to be

$v_{0}= \begin{cases}v_{0, S / 4} \sin \frac{2 \pi s}{S} & \text { for arches with } \geq 9.38 \\ v_{0, S / 2} \sin \frac{\pi s}{S} & \text { for arches with }<9.38\end{cases}$

for pin-ended arches, and

$v_{0}= \begin{cases}\frac{v_{0, S / 4}}{2}\left(1-\cos \frac{2 \pi s}{S / 2}\right) & \text { for arches with } \geq 18.6 \\ \frac{v_{0, S / 2}}{2}\left(1-\cos \frac{2 \pi s}{S}\right) & \text { for arches with }<18.6\end{cases}$

for fixed arches, where $v_{0, S / 4}$ and $v_{0, S / 2}$ is the initial in-plane crookedness at the quarter point and the crown of the arch length respectively, and $s$ is the coordinate along the arch axis. The expression for the imperfection satisfies the kinematical boundary conditions for the members.

The central crookedness implied by the Australian steel structures design code AS4100 [13] for the major axis strength of steel columns was obtained by Bild and Trahair [24], which is used in this study as the initial crookedness $v_{0, S / 4}$ at the quarter point of the arch length, so that

$\frac{1000 v_{0, S / 4}}{S / 2}=2.5\left(1-\frac{1}{1+2 \lambda_{c}}\right)$ or $\frac{1000 v_{0, S / 2}}{S}=2.5\left(1-\frac{1}{1+2 \lambda_{c}}\right)$,

where $\lambda_{c}$ is the modified slenderness of the corresponding column given by

$\lambda_{c}=\sqrt{\frac{N_{Y}}{N_{c r}}}$.

The variations of the dimensionless in-plane axial compressive strength $N_{a c} / N_{Y}$ with the modified in-plane slenderness $\lambda_{a c}$ obtained from the FE results are shown in Figure 5 for pin-ended arches and in Figure 6 for fixed arches, where the modified in-plane slenderness $\lambda_{a c}$ is defined as

$\lambda_{a c}=\sqrt{\frac{N_{Y}}{N_{a c r}}}$.

Also shown in Figures 5 and 6 is the variation of the dimensionless proposed in-plane strength of fixed arches $N_{a c} / N_{Y}$ with the modified in-plane slenderness $\lambda_{a c}$. It can be seen that the proposed equation provides good predictions for the in-plane strengths of arches in uniform compression.

It worth pointing out that for a pin-ended arch with $\lambda<3.88$ or a fixed arch with $\lambda<9.87$ that is subjected to a radial load uniformly distributed around it, the arch becomes very shallow and can be treated as a beam with initial in-plane geometric imperfection. Hence, the proposed Eq. 10 is not suitable in these cases. 


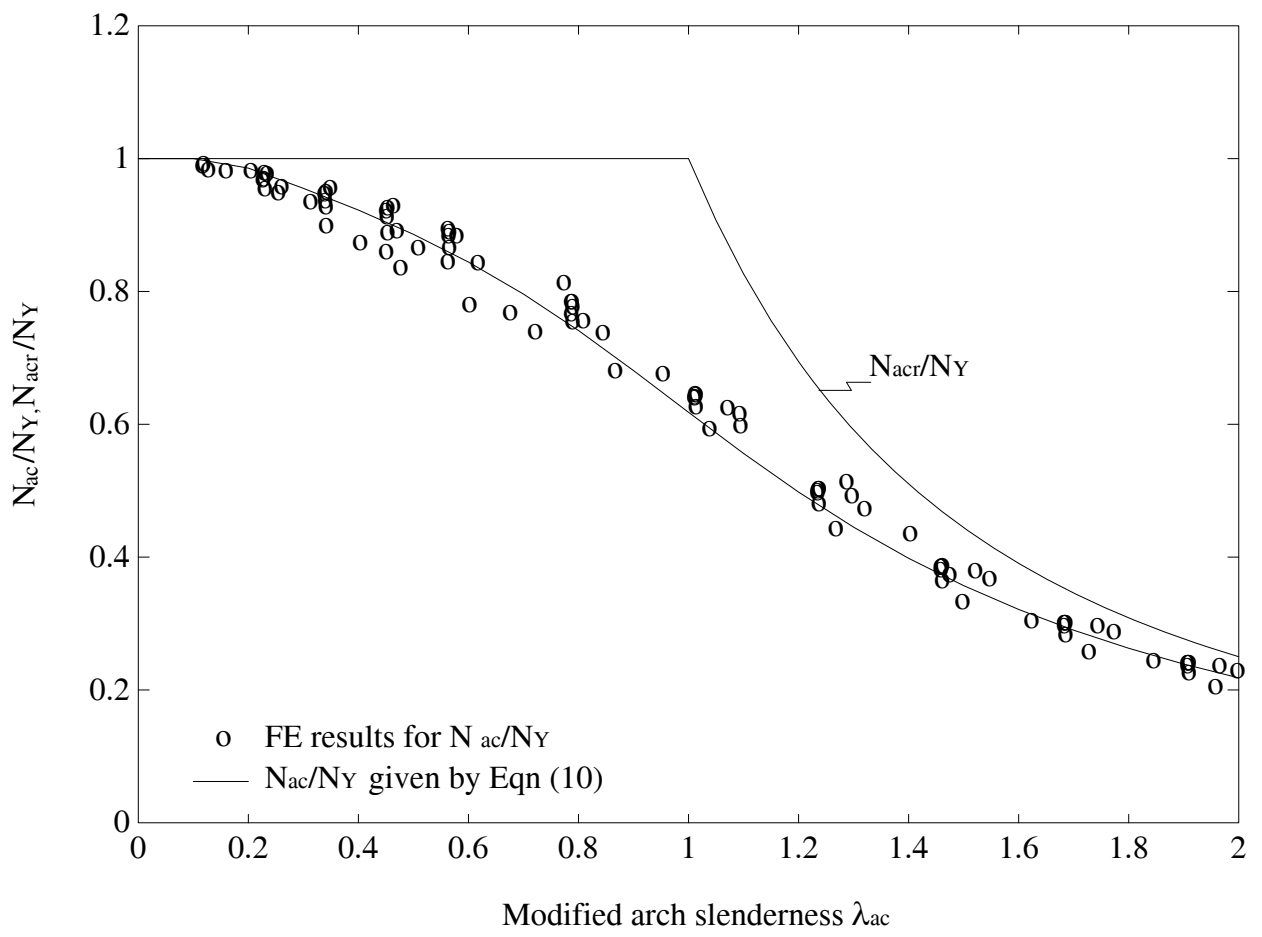

Figure 5. In-Plane Strength of Pin-Ended Arches Subjected to Uniform Compression

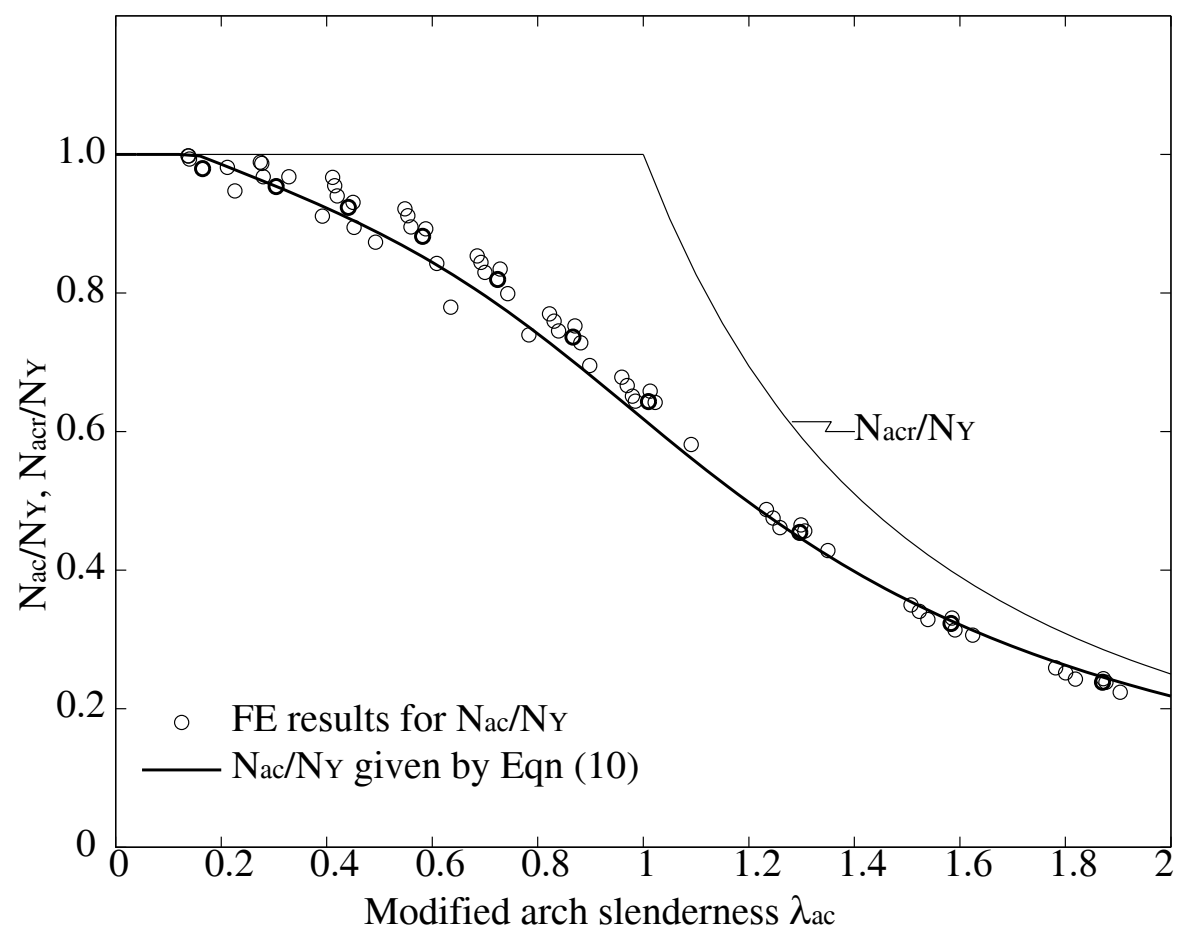

Figure 6. In-Plane Strength of Fixed Arches Subjected to Uniform Compression 


\section{STRENGTH IN COMBINED BENDING AND COMPRESSION}

\subsection{First-Order Actions in Elastic Arches}

Under general loading, arches are subjected to combined bending and axial compressive actions. Whether or not the compressive action or the bending action is significant relative to each other very much depends on the loading condition.

To investigate the effects of the loading condition on the bending and compressive actions, first-order elastic analyses were performed by using the flexibility method. For the design convenience, four loading cases were investigated: a central concentrated load, a quarter point concentrated load, a vertical load uniformly distributed over the entire span of an arch, and a vertical load uniformly distributed over a half of the span of an arch (Figure 1).

The results for the maximum compressive action $N$ and the maximum bending action $M$ are shown in Figure 7 as the relationship between the ratio $\left(N / N_{Y}\right) /\left(N / N_{Y}+M / M_{p}\right)$ and the included angle $\Theta$ for arches with length $S=10 \mathrm{~m}$, where $M_{p}$ is the full plastic moment of the cross-section. When an arch is subjected to a vertical load uniformly distributed over its entire span, the axial compressive action is relatively high and the bending action is relatively low. In addition, the compressive action in arches with a moderate included angle $\Theta$ is relatively higher than that in arches with a small or large included angle $\Theta$. When an arch is subjected to a vertical load uniformly distributed over a half of its span, to a central concentrated load, or to a quarter point concentrated load, the axial compressive action is relatively low and the bending action is relatively high. When the included angle $\Theta$ of an arch is very small, the bending action is relatively significant for all the four loading cases.

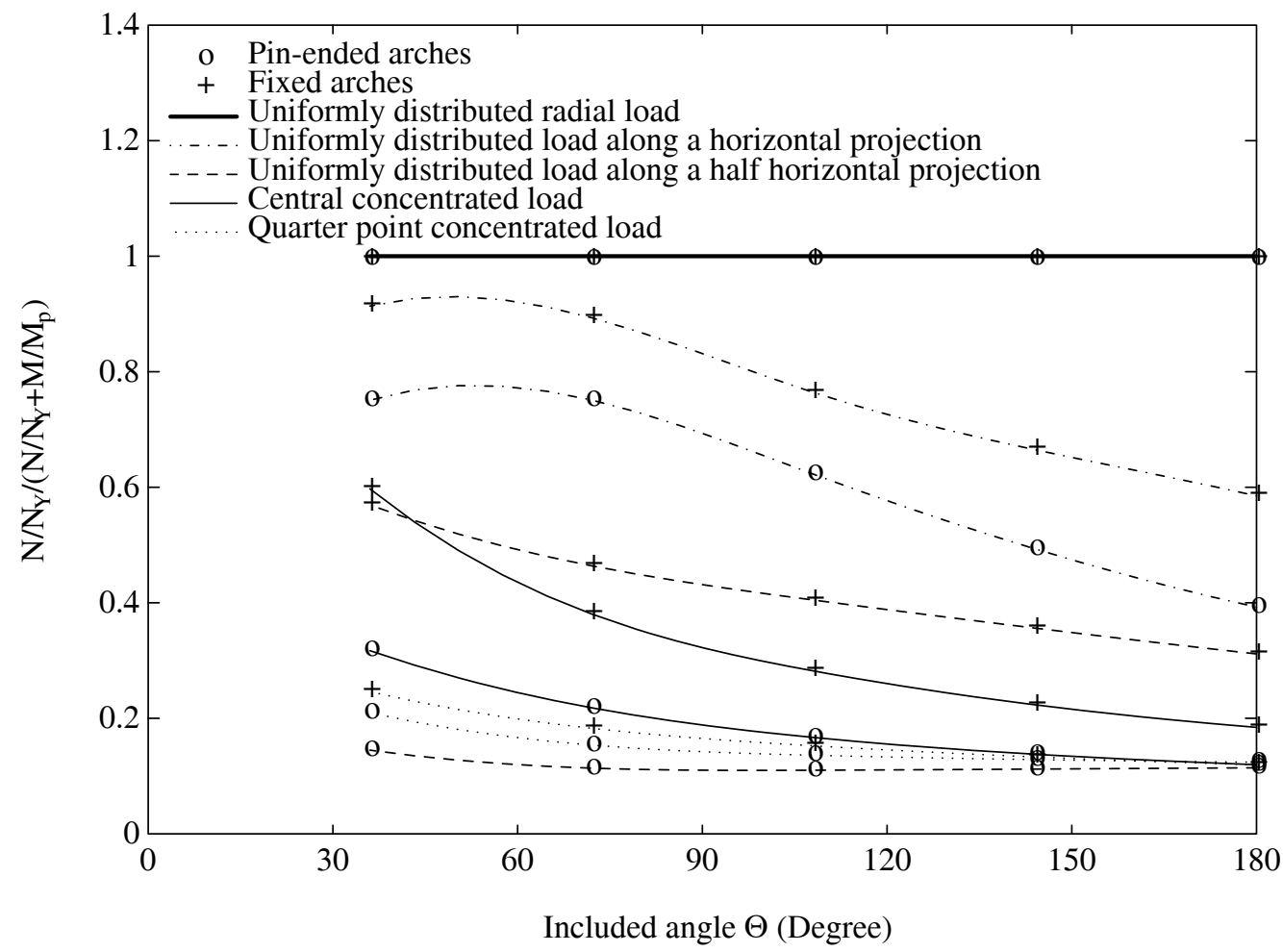

Figure 7. Maximum First-Order Bending Moment and Axial Compressive Force in Arches 


\subsection{Elastic and Elastic-Plastic Behaviour}

Typical in-plane elastic and elastic-plastic behaviours of four pin-ended arches (with $0.5 S / r_{x}=50$ ) under central concentrated loads are compared with those under quarter point loads in Figure 8, where $Q$ is the concentrated load, $v_{c}$ is the central vertical deflection for a central load, and $v_{L / 4}$ is the quarter point vertical deflection for a quarter point load. The included angles $\Theta$ and parameters $\lambda$ of these four arches are $\Theta=6.9^{\circ}, 11.5^{\circ}, 47^{\circ}$, and $160^{\circ}$ and $\lambda=3,5,20.5$, and 70 . These arches are assumed to be perfect, and so buckling is initiated by a small horizontal load $\left(Q=0.001 N_{E 1}\right)$ at the arch crown in the case of a central load.
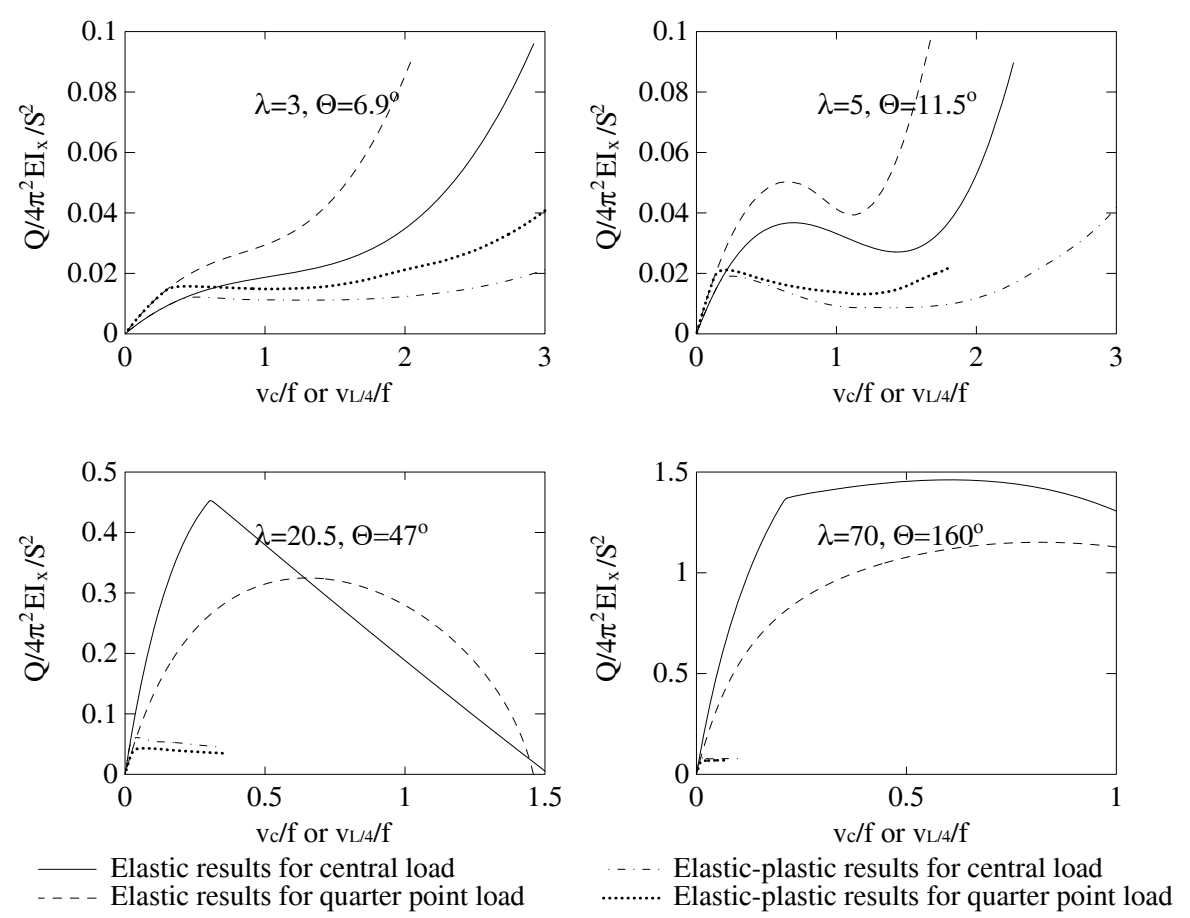

Figure 8. Elastic and Elastic-Plastic Behaviour of Pin-Ended Steel Arches Under Concentrated Loads

For the arch with $\lambda=3\left(\Theta=6.9^{\circ}\right)$, there is no elastic buckling, but elastic-plastic snap-through buckling occurs in both load cases. For the arch with $\lambda=5\left(\Theta=11.5^{\circ}\right)$, both the elastic and elastic-plastic buckling modes are by snap-through in both load cases. For the arch with $\lambda=20.5$ ( $\lambda$ $=20.5$ ) and a central load, the elastic buckling mode is by anti-symmetrical bifurcation and the postbuckling loads decrease rapidly. For a quarter point load, the elastic load-deflection curve is quite nonlinear and the load increases to a maximum value at a large deflection $\left(v_{L / 4} / f=0.64\right)$, and then decreases gradually. However, the elastic-plastic behaviour is similar to that for a central load. For the arch with $\lambda=70\left(\Theta=160^{\circ}\right)$ and a central load, the elastic buckling mode is also by anti-symmetrical bifurcation but the postbuckling loads increase slightly. For a quarter point load, the elastic load-deflection curve is quite nonlinear and the maximum load is reached at a large deflection $\left(v_{L / 4} / f=0.81\right)$. However, the elastic-plastic behaviour is similar to that for a central load.

The ratios of the elastic-plastic buckling load to the elastic buckling load for shallow arches $(\lambda=3$ and 5) are higher than those for non-shallow arches $(\lambda=20.5$ and 70$)$. The elastic and elastic-plastic buckling loads for quarter point loads are higher than those for central loads for shallow arches, but lower than those for central loads for non-shallow arches. 
The variations of the dimensionless strengths $Q /\left(4 \pi^{2} E I_{X} / S^{2}\right)$ or $q L /\left(4 \pi^{2} E I_{X} / S^{2}\right)$ with the parameter $\lambda$ and the arch included angle $\Theta$ for four groups of arches with slendernesses $0.5 S / r_{x}=30,50,110$, and 170 are shown in Figure 9 for concentrated loads where $Q$ is the maximum finite element value of the central or quarter point concentrated load, and in Figure 10 for uniform vertical loads where $q$ the maximum finite element value of the intensity of distributed load. The effects of the included angle $\Theta$ and the parameter $\lambda$ on the strengths are significant for the arches subjected to symmetrical loads (a central concentrated load in Figure 9 and an entire arch uniform load in Figure 10), particularly when $\lambda<10$, but less important for the arches subjected to asymmetrical loads (a quarter point load in Figure 9 and a half arch uniform load in Figure 10).
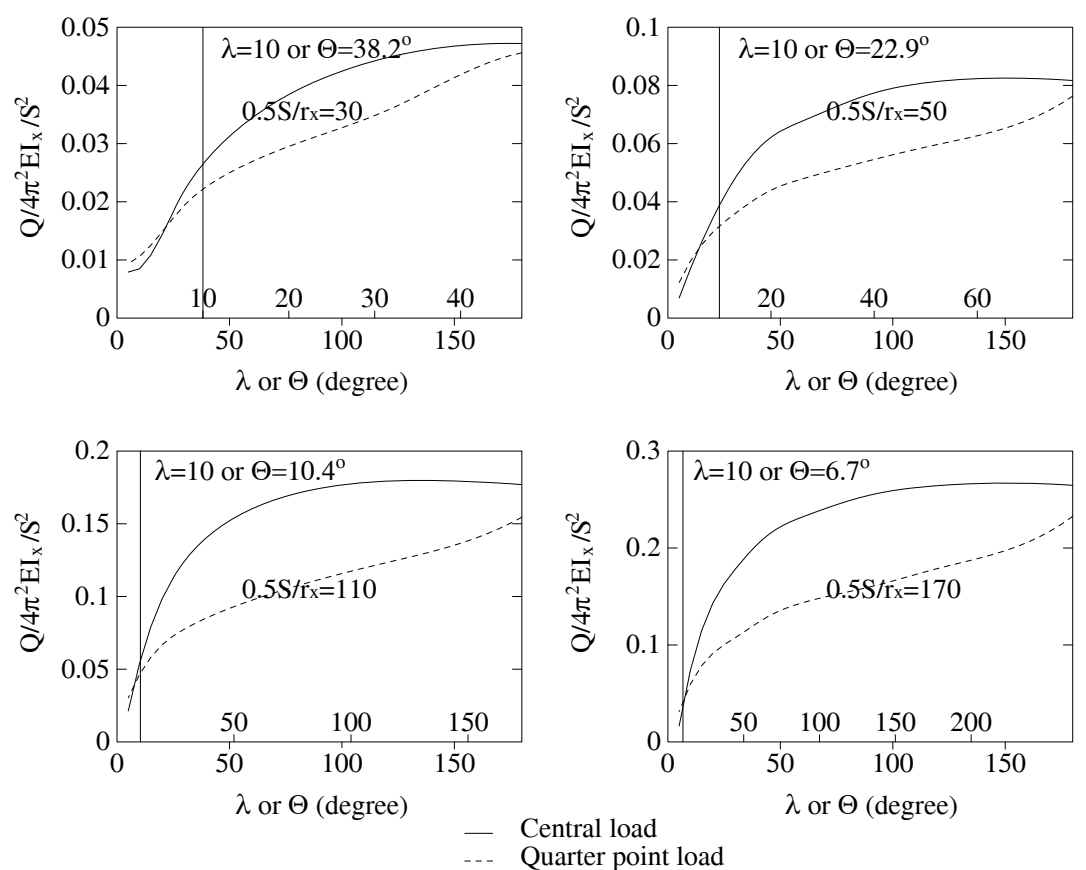

Figure 9. Strength of Pin-Ended Steel Arches Under Concentrated Loads
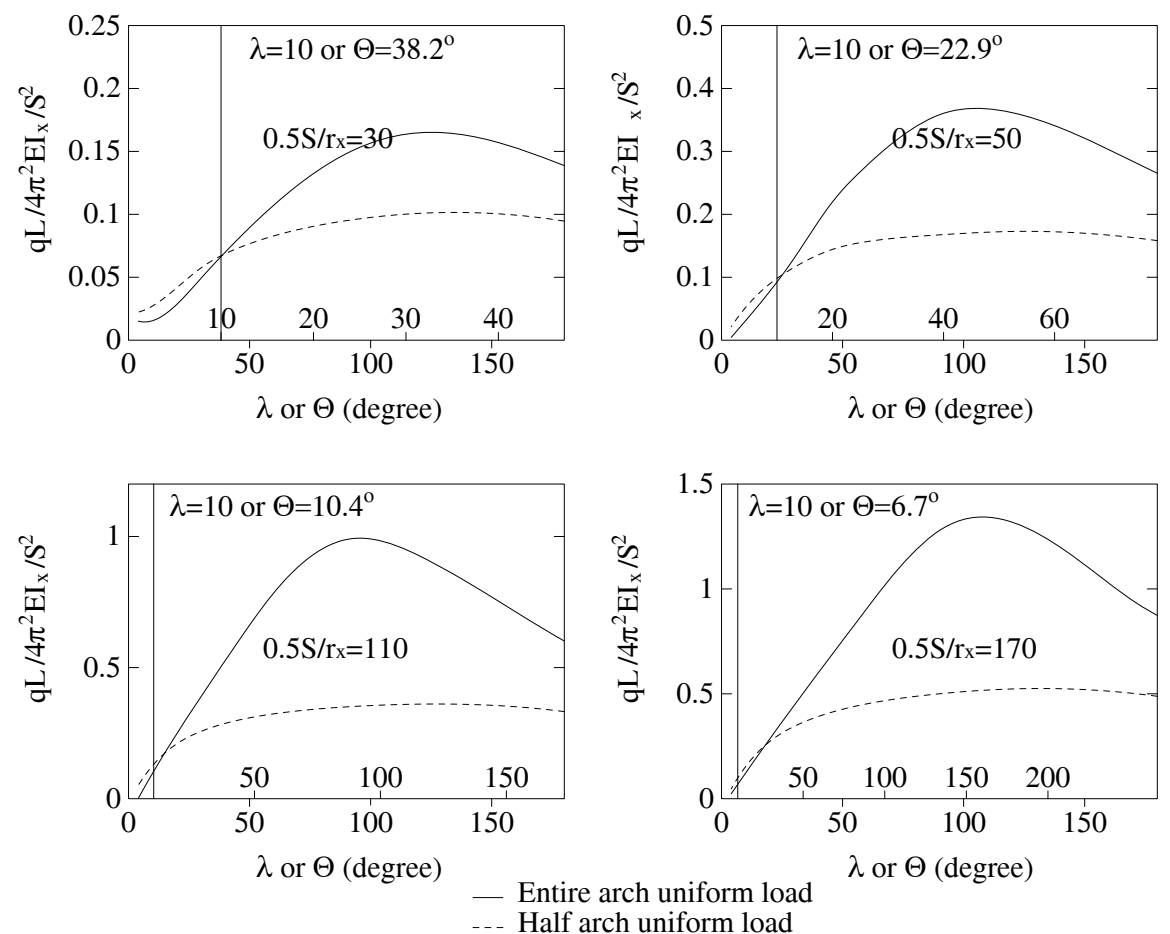

Figure 10. Strength of Pin-Ended Steel Arches Under Distributed Loads 


\subsection{In-Plane Design Strength}

The in-plane strength of a steel arch subjected to combined bending and axial compressive actions is complex, and is related to a number of factors, such as the buckling behaviour, yielding, the initial curvature, the included angle, the slenderness, the shallowness, residual stresses, initial in-plane geometric imperfections, and loading conditions. It is therefore difficult to develop simple and accurate equations for the design of arches that are subjected to the combined bending and axial compressive actions against in-plane failure. Instead, a lower bound interaction equation for the in-plane strength of arches has been sought based on the accurate numerical results.

The in-plane strength capacity design check for a steel arch that is subjected to combined bending and axial compressive actions is proposed as

$\frac{N^{*}}{\phi \alpha_{a n} N_{a c}}+\frac{M^{*}}{\phi \alpha_{a m} M_{p}} \leq 1$,

where $\phi$ is the same capacity reduction factor for uniform compression, $N_{a c}$ is the in-plane axial compression capacity of an arch in uniform compression given by Eq. 10, $N^{*}$ is the maximum axial compression obtained by a first-order in-plane elastic analysis, $M^{*}$ is the maximum moment given by

$M^{*}=\delta_{b} M_{m} \quad$ with $\quad \delta_{b}=\frac{1}{1-N^{*} / N_{a c r}}$

where $M_{m}$ is the maximum moment obtained by a first-order in-plane elastic analysis and $N_{a c r}$ is the in-plane elastic buckling load of an arch in uniform compression and given by Eqs. 2-5, and $\alpha_{a n}$ and $\alpha_{a m}$ are the axial compression and moment modification factors for the in-plane strength.

The modification factor $\alpha_{a m}$ accounts for the combined effects of the initial curvature, the included angle and the slenderness of the arch, and the non-uniform distribution of bending moment over the arch length, while the modification factor $\alpha_{a n}$ accounts for the non-uniform distribution of axial compressive force over the arch length. The effects of the included angle and the slenderness of the arch have already been accounted in the in-plane axial compression capacity $N_{a c}$. The values of $\alpha_{a n}$ and $\alpha_{a m}$ are given in Figure 11 for pin-ended arches and in Figure 12 for fixed arches.

\begin{tabular}{|c|c|c|c|c|c|}
\hline \multicolumn{2}{|r|}{ Arch } & 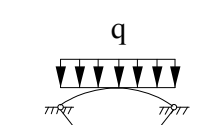 & $\frac{|I / 2|}{W V q}$ & $\mathrm{P}^{\mathrm{Q}} \stackrel{\mathrm{L} / 4}{\rightarrow}$ & Q \\
\hline \multicolumn{2}{|r|}{$\alpha_{\text {an }}$} & 1.00 & 1.00 & 1.10 & 1.10 \\
\hline \multirow{2}{*}{$\alpha_{\mathrm{am}}$} & $\lambda<9.38$ & $1.13+0.146 \lambda$ & $1+0.021 \lambda$ & $1.35+0.069 \lambda$ & $1.1+0.053 \lambda$ \\
\hline & $\begin{array}{ll}\lambda & 9.38\end{array}$ & 2.50 & 1.20 & 2.00 & 1.60 \\
\hline
\end{tabular}

Figure 11. Factors for in-Plane Strength of Pin-Ended Arches 


\begin{tabular}{|c|c|c|c|c|c|}
\hline \multicolumn{2}{|r|}{ Arch } & 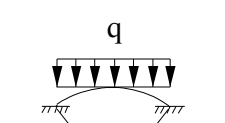 & 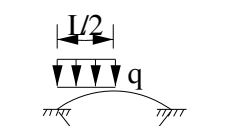 & $Q$ & $\underset{\pi \mid t}{\mathrm{~L} / 4}$ \\
\hline \multicolumn{2}{|r|}{$\alpha_{\text {anx }}$} & 1.00 & 1.00 & 1.10 & 1.10 \\
\hline \multirow{2}{*}{$\alpha_{\mathrm{amx}}$} & $\lambda<18.6$ & $\begin{array}{c}2.0+ \\
0.1(18.6-\lambda) \Theta / \pi\end{array}$ & $\begin{array}{c}1.20^{+} \\
0.5(18.6-\lambda) \Theta / \pi\end{array}$ & $\begin{array}{c}1.50^{+} \\
0.05(18.6-\lambda) \Theta / \pi\end{array}$ & $\begin{array}{c}1.80+ \\
0.05(18.6-\lambda) \Theta / \pi\end{array}$ \\
\hline & $\lambda>18.6$ & 2.0 & 1.20 & 1.50 & 1.80 \\
\hline
\end{tabular}

Figure 12. Factors for in-Plane Strength of Fixed Arches

It is recommended that if the amplification factor $\delta_{b}>1.4$, then a second-order in-plane elastic analysis should be carried out to obtain $M^{*}$ and $N^{*}$. This recommendation is consistent with that of $A S 4100^{13}$ for frames consisting of straight members.

The predictions of the proposed interaction Eq. 21 are compared with the FE results (taking $\phi=1$ ) for four load cases: a central concentrated load, a quarter point concentrated load, a uniformly distributed load over the entire arch, and a uniformly distributed load over a half of the arch (Figure 1). In the FE analysis, the initial in-plane imperfections defined by Eqs. 16-18 were used.

Comparisons of the predictions of the proposed Eq. 21 with the FE results are shown in Figures 13 and 14 for pin-ended arches that are subjected to symmetric and asymmetrical loads respectively, and in Figures 15 and 16 for fixed arches that are subjected to symmetric and asymmetric loads respectively. It can be seen that the interaction Eq. 21 provides good lower bound predictions that are not unduly conservative for the in-plane strength of steel arches that are subjected to the combined bending and axial compressive actions.

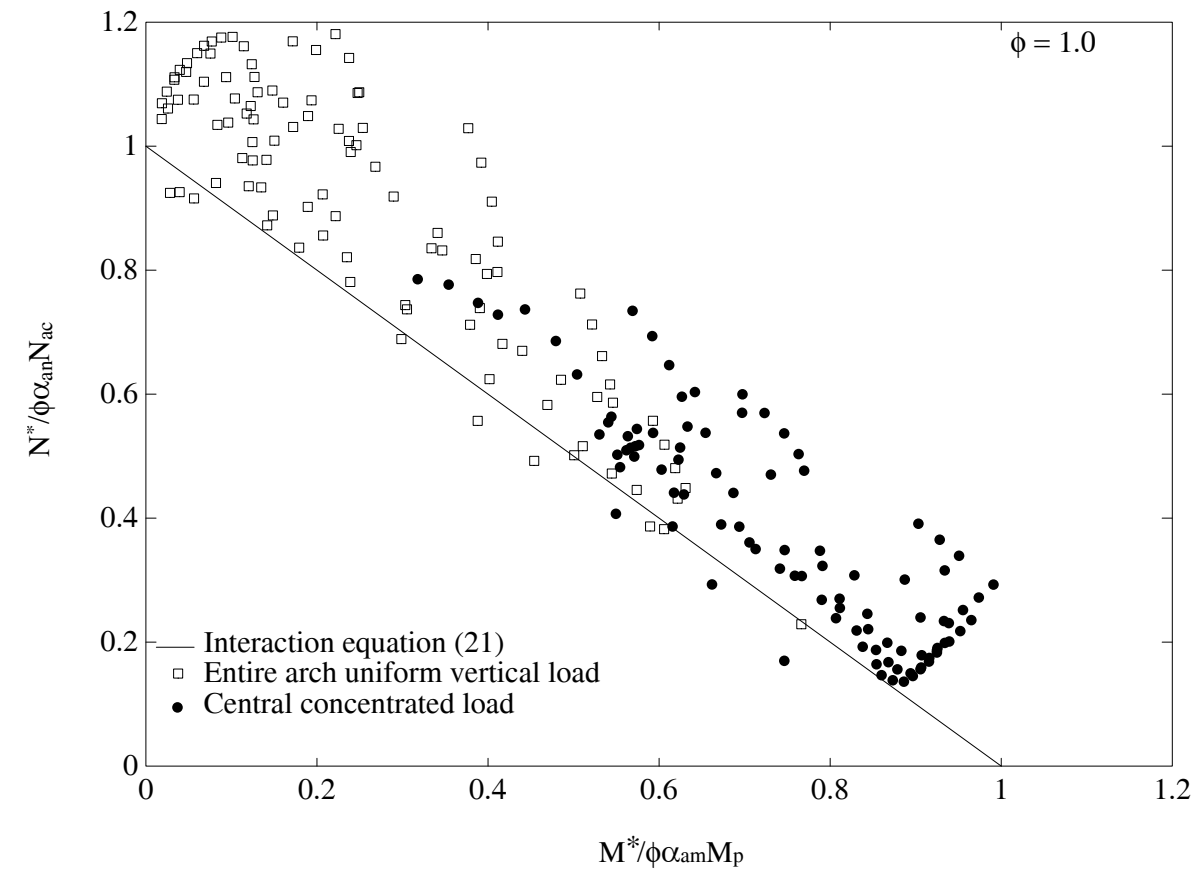

Figure 13. In-plane strength of pin-ended arches subjected to symmetric loading. 


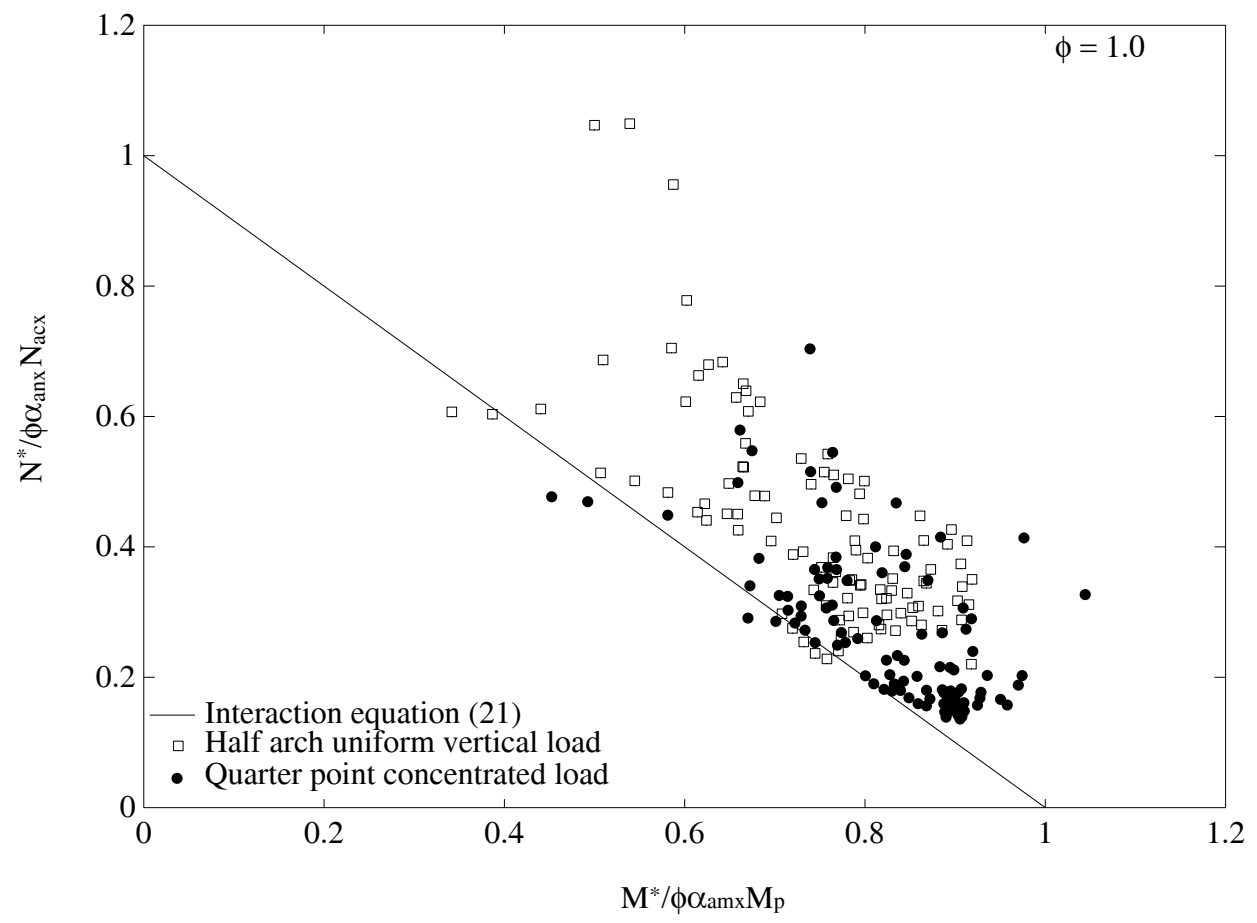

Figure 14. In-plane strength of pin-ended arches subjected to asymmetric loading.

Again, it is noted that for a pin-ended arch with $\lambda<3.88$ or a fixed arch with $\lambda<9.87$ that is subjected to a radial load uniformly distributed around it, the arch becomes very shallow and can be treated as a beam with initial in-plane geometric imperfection. Hence, the proposed Eq. 21 is not suitable in this case.

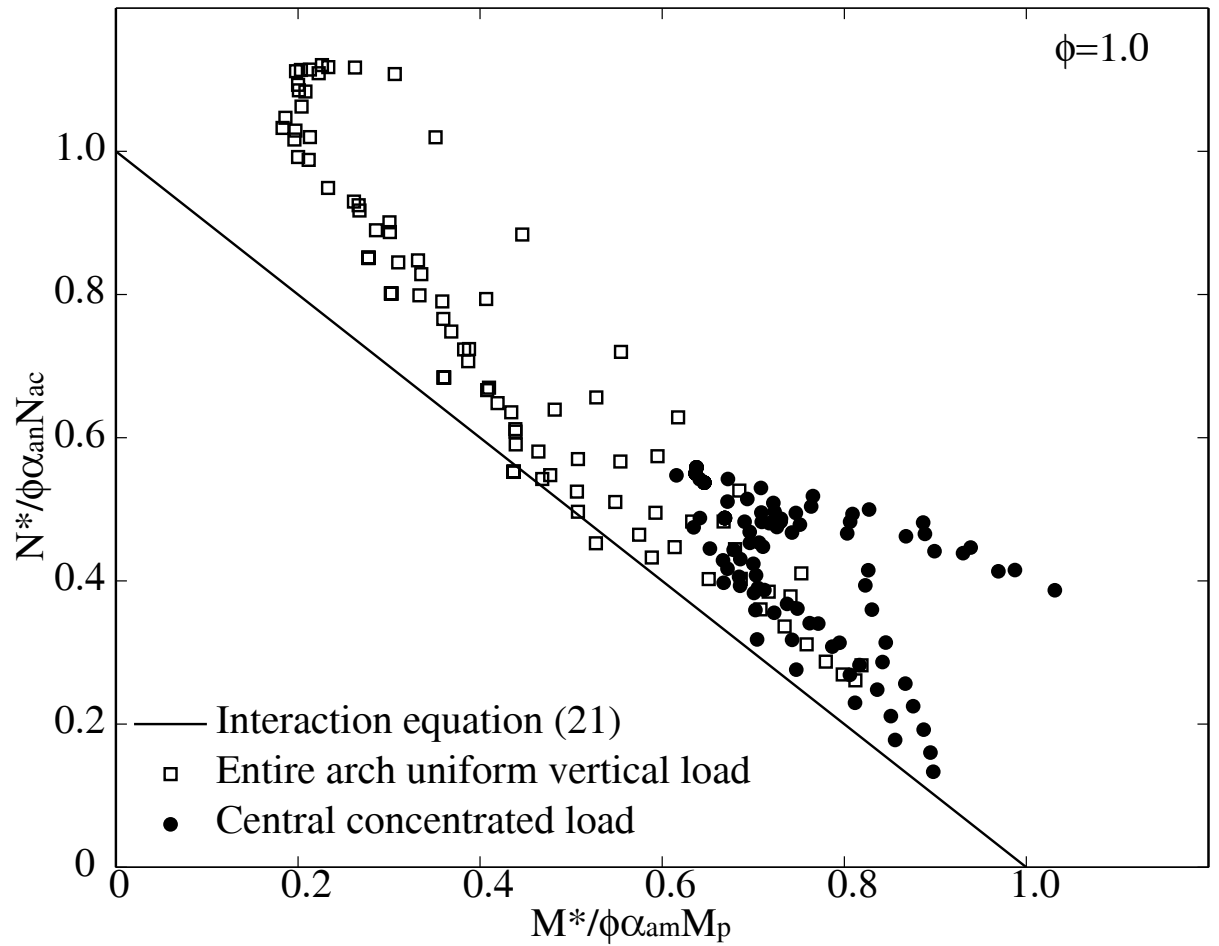

Figure 15. In-plane strength of fixed arches subjected to symmetric loading. 


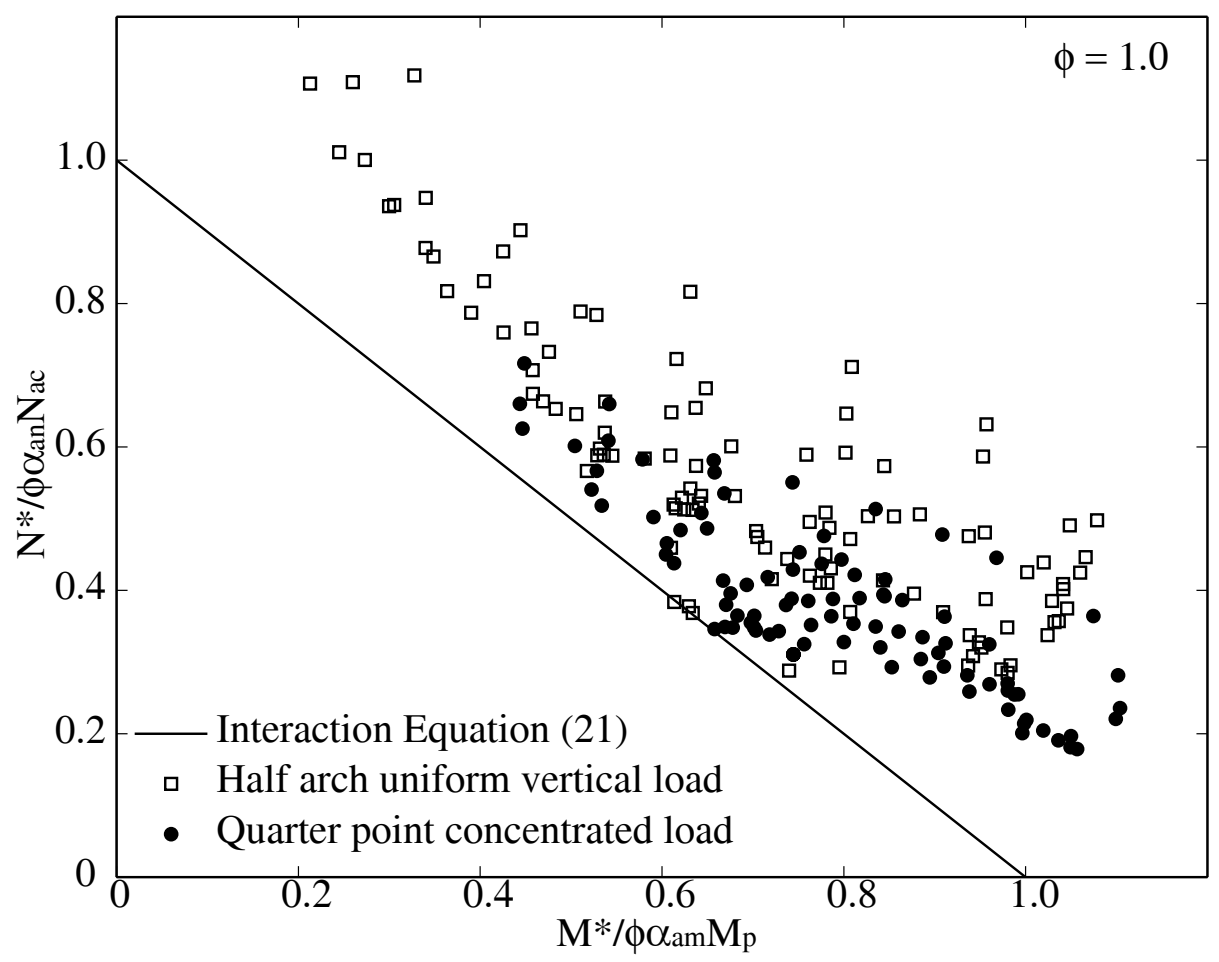

Figure 16. In-plane strength of fixed arches subjected to asymmetric loading.

\section{CONCLUSIONS}

A design equation for the in-plane strength of steel arches in uniform compression has been proposed which provides good predictions for their in-plane strength. An interaction equation for the in-plane design strength of steel arches that are subjected to the combined bending and axial compressive actions has also been proposed. It considers the effects and interactions of various factors, such as in-plane buckling, yielding, the included angle, the slenderness, the shallowness, residual stresses, initial in-plane geometric imperfections, non-uniform distributions of bending moments and axial compressive forces, loading conditions. The proposed design interaction equation is simple and easy to use, is consistent with the Australian steel structures design code AS4100 [13], and may easily be formulated for other steel structural design codes. Generally, a first-order or second-order in-plane elastic analysis is sufficient for the design. The proposed design equation provides good lower bound predictions for the in-plane strength of steel arches that are subjected to the combined bending and axial compressive actions.

\section{ACKNOWLEDGEMENTS}

This work has been supported by the Australian Research Council through Discovery Projects awarded to the authors and a Federation Fellowship awarded to the second author. 


\section{REFERENCES}

[1] Timoshenko, S.P. and Gere, J.M., "Theory of Elastic Stability", 2nd Edition, McGraw-Hill, 1961.

[2] Vlasov, V.Z., "Thin-walled Elastic Beams", 2nd Edition, Israel Program for Scientific Translation, 1961.

[3] Simitses, G.J., "An Introduction to the Elastic Stability of Structures", Prentice-Hall, Englewood Cliffs, 1976.

[4] DaDeppo, D.A. and Schmidt, R., "Nonlinear Analysis of Buckling and Postbuckling Behavior of Circular Arches", Journal of Applied Mathematics and Physics, 1969, Vol. 20, pp. 847-857.

[5] Austin, W.J. and Ross, T. J., "Elastic Buckling of Arches under Symmetric Loading", Journal of the Structural Division, ASCE, 1976, Vol. 102, No. 5, pp. 1085-1095.

[6] Chini, S.A. and Wolde-Tinsae, A. M., "Critical Load and Postbuckling of Arch Frameworks", Journal of Engineering Mechanics, ASCE, 1988, Vol. 114, No. 9, pp. 1435-1453.

[7] Mirmiran, A. and Wolde-Tinsae, A.M., "Buckling and Postbuckling of Prestressed Sandwich Arches", Journal of Structural Engineering, ASCE, 1993, Vol. 119, No. 1, pp. 262-278.

[8] Galambos, T.V., "Guide to Stability Design Criteria for Metal Structures", $4^{\text {th }}$ Ed, John Wiley \& Sons, 1988.

[9] Pi, Y.-L. and Trahair, N.S., "Non-linear Buckling and Postbuckling of Elastic Arches", Engineering Structures, 1998, Vol. 20, No. 7, pp. 571-579.

[10] Gjelsvik, A. and Bodner, S.R., "The Energy Criterion and Snap Buckling of Arches", Journal Engineering of the Mechanic Division, ASCE, 1962, Vol. 88, No. 5, pp. 87-134.

[11] Schreyer, H.L. and Masur, E.F., "Buckling of Shallow Arches", Journal of the Engineering Mechanic Division, ASCE, 1966, Vol. 92, No. 4, pp. 1-20.

[12] Pi, Y.-L., Bradford, M.A., and Uy, B., "In-plane Stability of Arches", International Journal of Solids and Structures, 2002, Vol. 39, No. 2, pp. 105-125.

[13] "AS4100, Steel structures", Standards Australia, 2003.

[14] "BS5950, Structural Use of Steel in Building, Part 1, Code of Practice for Design in Simple and Continuous Construction: Hot-Rolled Sections", British Standards Institution, 1998.

[15] "Load and Resistance Factor Design Specification for Structural Steel Buildings", American Institute of Steel Construction, 2000.

[16] Komatsu, S. and Shinke, T., "Practical Formulation for In-Plane Load Carrying Capacity of Arches", Proceedings of Japan Society of Civil Engineers, 1977, Vol. 267, pp. 39-52, Tokyo, Japan, (in Japanese).

[17] Kuranishi, S. (Ed.), "Chapter 7 Arches", Stability of Metal Structures - A World View. 2nd Ed, Ed by L.S. Beedle, Structural Stability Research Council, Bethlehem, Pa., pp. 423-445, 1991.

[18] Verstappen, I., Snijder, H.H., and Bijlaard, F.S.K. and Steembergen, H.M.G.M., "Design Rules for Steel Arches-in-Plane Stability", Journal of Constructional Steel Research, 1998, Vol. 46, No. 1-3, pp. 125-126.

[19] Pi, Y.-L. and Trahair, N.S., "In-Plane Inelastic Buckling and Strength of Steel Arches", Journal of Structural Engineering, ASCE, 1996, Vol. 122, No. 7, pp. 734-747.

[20] Pi, Y.-L. and Trahair, N.S., "In-Plane Buckling and Design of Steel Arches", Journal of Structural Engineering, ASCE, 1999, Vol. 125, No. 11, pp. 1291-1298.

[21] Pi, Y.-L. and Bradford, M.A., "In-Plane Strength and Design of Fixed Steel I-Section Arches", Engineering Structures, 2004, Vol. 26, No. 3, pp.291-301. 
[22] Pi, Y.-L., Bradford, M.A., Tin-Loi, F., and Gilbert, R.I., "Geometric and Material Nonlinear Analysis of Elastically Restrained Arches", Engineering Structures, 2007, Vol. 29, No. 3, pp. 283-295.

[23] Pi, Y.-L., Bradford, M.A., and Uy, B., "A rational Elasto-plastic Spatially Curved Thin-walled Beam Element", International Journal for Numerical Methods in Engineering, 2007, Vol. 70, pp. 253-290.

[24] Bild, S. and Trahair, N.S., "Steel Column Strength Models", Journal of Constructional Steel Research, 1988, Vol. 11, pp. 13-26. 